\title{
Potential of A Two-Stroke Direct InjeCtion Engine
}

\author{
Steffen Theiss, Claus Breuer \& Johannes Ullrich
}


This Publication has to be referred as: Theiss, S[teffen]; Breuer, C[laus] \& Ullrich, J[ohannes] (2020). Potential of a Two-Stroke Direct Injection Engine, Proceedings of the 31st DAAAM International Symposium, pp.0877-0883, B. Katalinic (Ed.), Published by DAAAM International, ISBN 978-3-902734-29-7, ISSN 1726-9679, Vienna, Austria DOI: $10.2507 / 31$ st.daaam.proceedings. 122

\begin{abstract}
Electrification seems to be the pioneering opportunity for the future means of mobility. Nevertheless, internal combustion engines will still dominate as power unit for passenger traffic for many years and must therefore become even more sustainable and affordable. Currently the MPI-Spark-Ignition engine dominates the passenger car segment, but shows only limited potential to meet the worldwide targets for CO2 emission until 2030 and 2050. A research matrix shows that high NOx, sound and vibration emissions are caused by high combustion pressure and temperature conditions. Especially in four-stroke diesel engines these conditions are produced due to a combustion of high injected fuel volume. To produce the same engine specific power output another combustion principle is needed. The concept of a simple two-stroke compression ignition engine, so called TSDI (Two Stroke Direct Injection), derived from an existing 4-stroke hardware, presented in this paper is built to verify the hypothesis, that lower injected fuel volume equals to lower NOx, sound and vibration emissions. These initial tests show huge potential to reduce raw-emissions (especially NOx and CO2) and noise level (comfort), combined with evident cost-savings and compatibility with today's vehicle architectures and energy infrastructure.
\end{abstract}

Keywords: two-stroke diesel; low compression ratio; high EGR; traffic noise; low $\mathrm{NO}_{\mathrm{x}}$

\section{Introduction}

Individual mobility is going to be more important for the future. In the industrialized world more than every second person is a car owner and the numbers of vehicles per person is still rising. Nevertheless, the German government sets closer $\mathrm{CO}_{2}$ targets for 2030 and 2050. To guarantee individual mobility in the future a change of perspective especially in the car industry is necessary and ongoing. Nowadays, the focus is set on eco-friendly vehicles, particularly in the division of small and mid-range cars. This segment is dominated by MPI-spark-ignition-engines, which are not able to reach the $\mathrm{CO}_{2}$ emission targets until 2030 and 2050. Electric driven vehicles are supported by OEM's and by different government programs. This seems to be the current aim of supporting low emission mobility. Based on a report published by the German government in 2020, it is shown that if electric driven vehicles are solely supported, they will not be able to set down $\mathrm{CO}_{2}$ emissions [1]. This results into the fact that also lower emission MPI and Diesel vehicles must be developed. 
Based on a Private Partnership Project (PPP), a concept for future individual mobility is created with the aim of low $\mathrm{NO}_{\mathrm{x}}$, noise, and vibration-emission as well as low weight. Several partners from the automotive industry and a university provide the project with hardware, software and knowhow. The project consists of members of THM-University of Applied Science, TCU, Weisskopf Engineering, Neste, BASF, Shell, Debilas, Sprintex and Fuchs Oil, only to name a few.

To clarify the questions, why current produced engines have expensive exhaust after-treatment, extra sound absorption, ornate vibration dampers and heavy engine structure, a research matrix is needed. As the main reason it turns out, that higher engine power, like customers are searching for, especially the required higher injected fuel volume creates higher combustion pressure and temperature. The results are higher $\mathrm{NO}_{\mathrm{x}}$, noise and vibration emissions and also a heavier engine structure. To receive the same power output but still reach the named targets, another concept as the standard fourstroke principle is needed.

By focussing first on the exhaust emissions, it becomes evident that the conventional four-stroke engines emit, based on their process, a high amount of $\mathrm{NO}_{\mathrm{x}}$. Hence, the exhaust after treatment is going to be more expensive to received less $\mathrm{NO}_{\mathrm{x}}$-emissions. Higher costs in terms of development and product costs, also for customers, are expected [2]. Future emissions standards may not be reached with a conventional four-stroke diesel or MPI engine, which is an additional reason why a new basic concept is needed to minimize the emissions.

With new standardised technique, a two-stroke diesel engine must be used to reduce the $\mathrm{NO}_{\mathrm{x}}$-emissions, also for a better driving comfort and lower noise emissions. The principle applied is based on the fact that a two-stroke engine only needs one crankshaft revolution for one thermodynamic circle. Four-stroke engines need two revolutions. Hence, with the same engine speed, two-stroke engines have twice more ignitions as four-stroke engines. By the same theoretical power output, the fuel volume can be splitted into twice more ignitions. As a result, the injected volume is only half compared to a four-stroke process. Lower combustion temperature and pressure peaks can be reached. The lower the temperature the lower $\mathrm{NO}_{\mathrm{x}}$-emissions. In addition, the engine noise and vibration can be on a lower level because of the smoother pressure increase.

The two-stroke diesel engine is not new. Already in the 1980s many American trucks were driven by two-stroke diesel engines. Nonetheless, the technique of a two-stroke diesel was not able to compete against the four-stroke diesel. Nowadays standardised techniques in the diesel engine segment, such as Common Rail (CR) injection, turbochargers and engine control units (ECU), show more possibilities to build a new two-stroke diesel concept. A literature review shows, in the last 20 years, only Renault tested a new designed two-stroke engine [3]. A tremendous financial support by the European Union was used to simulate a theoretical engine concept. Official publications and results were not found after a research.

The members of the here described project took an established four-stroke three-cylinder engine with CR injection as a basis to build a two-stroke engine with several modifications. The data of the basic engine is shown in the following table:

\begin{tabular}{|l|l|}
\hline Cylinder & 3 \\
\hline Displacement & 1.11 \\
\hline Compression Ratio & 18 \\
\hline Power & $55 \mathrm{~kW}$ \\
\hline Rated RPM & $40001 / \mathrm{min}$ \\
\hline Engine Head & 4 Valves/cylinder, Crossflow, Swirlflap \\
\hline
\end{tabular}

Table 1. Four-stroke engine data [4]

The modifications are new designed camshafts, an extra supercharger and instead of the original ECU, a version with free-programmable software by Weisskopf Engineering. The gas is changed by the cylinder-head valves. Intake air gas flows in the cylinder via the inlet valves while the outlet valves are open for scavenge the exhaust gasses. The first milestone of the project is to build a running two-stroke engine. Results of this first milestone are given in this paper together with an outlook to expected benefits and future milestones.

\section{Theoretical targets}

Like explained above, the theoretical targets are:

- Lower NOx-emissions

- Lower noise level

- Less vibrations

- More driving comfort

- Less engine weight

- Cheaper engine parts 
The theory behind the $\mathrm{NO}_{\mathrm{x}}$-reduction is based on the fact, that a two-stroke engine needs less fuel for one cycle in comparison to a four-stroke engine. The lower combustion pressure and temperature equals to lower $\mathrm{NO}_{\mathrm{x}}$-emissions. The mechanism behind the reactions while combustion is called the Zeldowich-Mechanism. Zeldowich is describing, that NOx, the so called nitrogen (di)oxides, need high reaction temperatures, so that nitrogen and oxygen can react mainly to $\mathrm{NO}, \mathrm{NO}_{2}$. With combustion temperatures between 1500 and $1700 \mathrm{~K}$, the reactions to NOx molecules rise exponentially. Therefore, it is necessary to create a lower combustion temperature [5].

The basic four-stroke diesel used for the two-stroke transformation is an EURO 4 engine with 3 cylinder, turbocharger, Common Rail injection and twelve valves. In Figure 1 the basic engine is placed in the Euro 4 area. The target is to get $\mathrm{NO}_{\mathrm{x}}$-emissions like a state of the art EURO 6 or even better, like a Euro 6 gasoline engine. That means that less than a quarter of $\mathrm{NO}_{\mathrm{x}}$-emissions must be reached.



Fig. 1. Comparison between different emission laws

State of the art for CR direct injection technique are 2000 bar injection pressure and more [6]. High injection pressure can produce faster and small fuel drops. Such small fuel drops burn faster and at a higher temperature, because of the bigger surface for reaction with $\mathrm{O}_{2}$. This is one opportunity for reducing the forming of hydrocarbon particle.

Low $\mathrm{NO}_{\mathrm{x}}$-emissions can be reached with high rates of internal exhaust gas recirculation (EGR) due to an incomplete scavenging process, which is easy to implement with a two-stroke concept. In modern four-stroke engines external EGR is often used to reduce $\mathrm{NO}_{\mathrm{x}}$-emissions. An extra valve, the so called EGR-valve, is used to control the mass flow of exhaust gases into the cylinder. Such an EGR-valve is not necessary in the two-stroke engine, because of the high internal exhaust gases, like explained above.

The combination of high injection pressure and high EGR can reduce $\mathrm{NO}_{\mathrm{x}}$ and $\mathrm{HC}$-emissions at once [5]. But high EGR rates often lower the fuel efficiency because of the slower burning process. A fact, that has to be investigated and tuned up with special ECU settings [7]. For a lower $\mathrm{NO}_{\mathrm{x}}$ level, synthetic fuels or additives can be used. Also NVH can be reduced with ethanol or methanol as additives [8]. An additional advantage of the two-stroke project is a significant lower noise level, to be reached by a slower combustion, as explained above. The reason is a flatten rise of combustion pressure (bar) per crankshaft degree $\left({ }^{\circ} \mathrm{KW}\right)$ :

$$
\frac{d p}{d \alpha}\left\lceil\frac{b a r}{{ }^{\circ} K W}\right\rceil
$$

This can be used as an indicator for engine noise and vibration (NVH). With lower combustion pressure, the momentum of turning pikes are lower and the ignition frequency is two times higher. Figure 2 compares the theoretical tangential forces over the crankshaft rotation from a 3-cylinder four-stroke and a 3-cylinder two-stroke, indicating the improvement of vibration and noise level. 

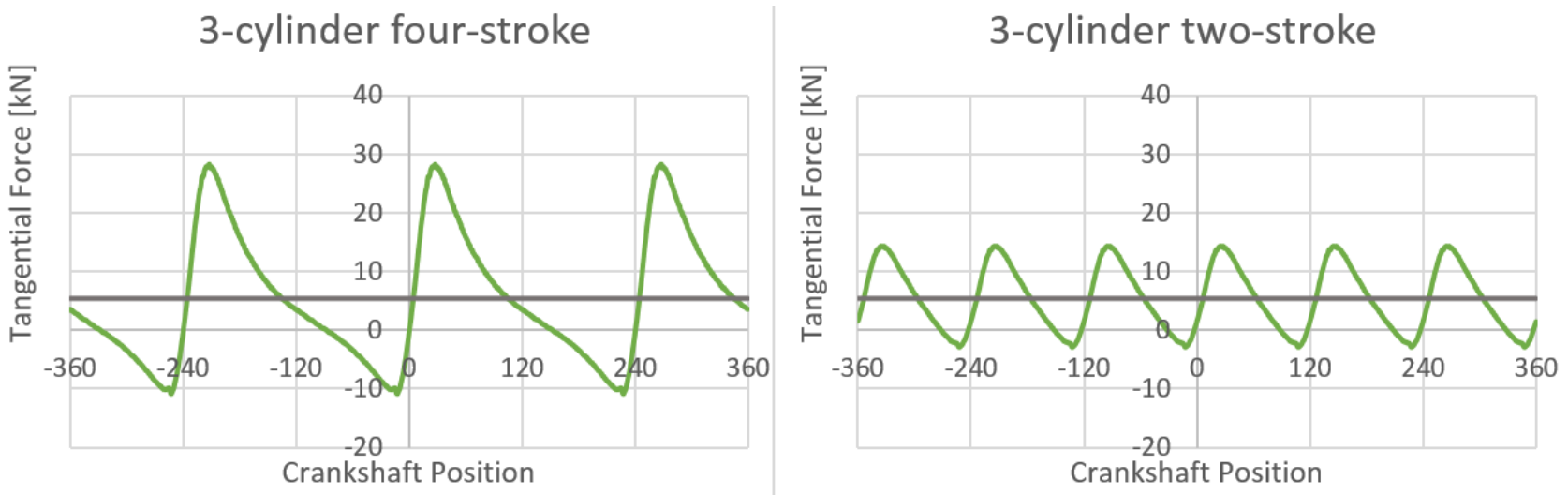

Fig. 2. Comparisson of the tangential force from 3-cylinder four-stroke and 3-cylinder tow-stroke engine

The grey line in Figure 2 represents the middle tangential force $F_{T, M}$, which has the same amount in the fore-stroke and two-stroke version. Focusing on the green line, the tangential force, big differences become visible. In the four-stroke version the peaks are double as high in comparison to the two-stroke version. It has also more negative tangential forces and the overall difference between top and bottom peaks are higher. All these aspects show that the two-stroke version has a smoother engine-run. A bonus in terms of driving comfort and engine design. The design of all parts inside the engine like piston, piston rod, crankshaft, also the engine block and flywheel can be much lighter in weight. Overall, the vehicle weight and furthermore lower rolling friction with a better fuel consumption are the advantages.

Like explained above, the two-stroke engine can be lighter and several parts like the EGR-valve and exhaust after treatment can be saved. Also the turbocharger is not needed, because of the additional supercharger. In summary, the twostroke engine can be a cheaper engine than a four-stroke engine is.

\section{Technical modifications}

Like explained in Chapter 2, three main modifications were made to get a running two-stroke diesel engine out of a fourstroke base. It includes a modified camshaft, a supercharger and a free programmable ECU, as shown in Fig. 3.


Fig. 3. Parts for the two-stroke modification

The camshaft chain drive and the engine block shall stay original, so for further transformation only the camshaft must be changed. That means the overall ratio from crank to camshaft will not be changed. A camshaft with double cams for each valve is designed basically with a two-stroke cam design.

In fact, because of a changed gas flow through the engine, an additionally supercharger is needed to produce compressed air for the scavenging process. The supercharger is powered by the drive belt. To receive the best fit supercharger, a special designed test bench is build. Figure 4 shows the schematic test bench, which contains a fitting for the contraction of the mass flow to be comparable to the inlet valve profile of the two stroke engine. In Table 2 all measuring-points are listed. 


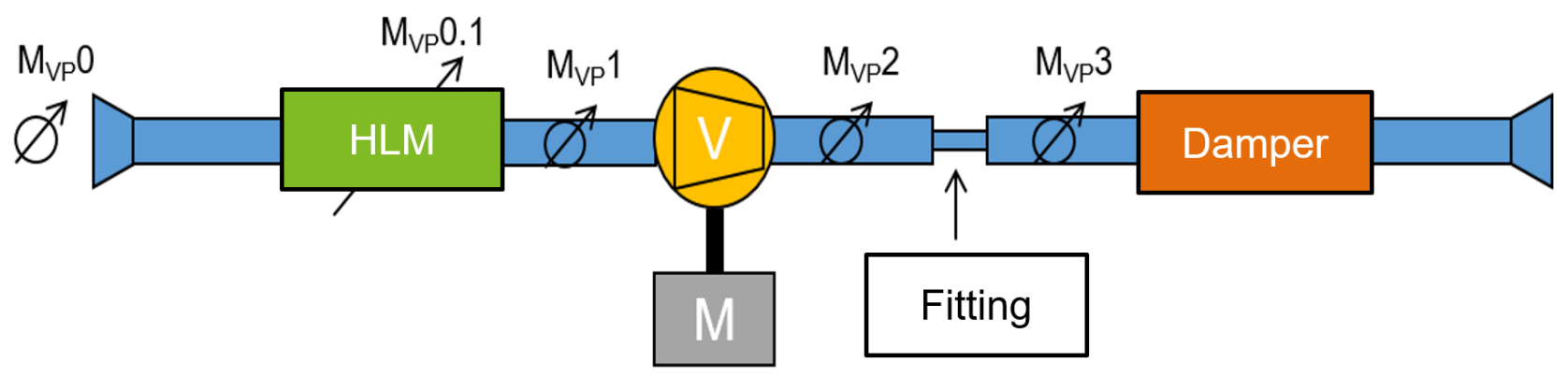

Fig. 4. Schematic design of the test bench for superchargers

Several superchargers were tested to fit the charger characteristic ideally to the demand of the engine. The smallest charger reaches $80 \mathrm{~kg} / \mathrm{h}$ and the tallest $300 \mathrm{~kg} / \mathrm{h}$. The main criteria to choose a supercharger is the need of power per scavenging pressure, given in $[\mathrm{kW} / \mathrm{mbar}]$. A fitting for mass flow contraction is mounted behind the supercharger. As a consequence of contraction, the air pressure is rising due to the mass flow.

A fitting for mass flow contraction is mounted behind the supercharger. As a consequence of contraction, the air pressure is rising due to the mass flow. The higher the mass flow the higher the pressure becomes. That pressure is the simulated scavenging pressure. The best supercharger is one with the highest mass flow because of the better efficiency by medium compression ratio of 1.2 to 1.5 . Another advantage is the lower noise level by less revolutions per minute (rpm) that is needed for the corresponding pressure compare to a smaller supercharger.

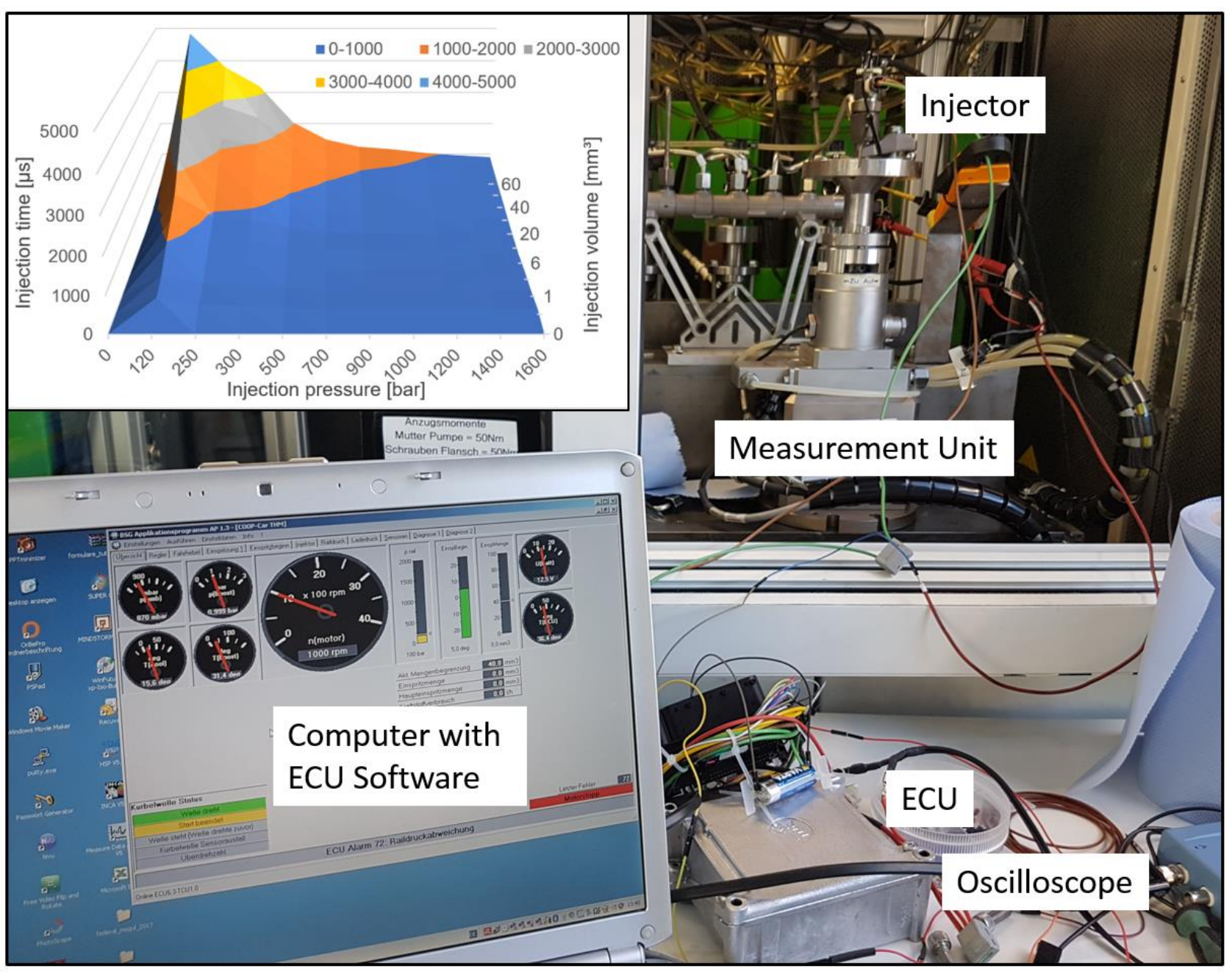

Fig. 5. CR injection test bench with free programmable ECU and injection time map 


\begin{tabular}{|l|l|l|}
\hline Measuring-point & Measurement & Unit \\
\hline$M_{\mathrm{vP} 0}$ & Environment pressure and temperature & $\mathrm{mbar}$ and ${ }^{\circ} \mathrm{C}$ \\
\hline$M_{\mathrm{vP} 0.1}$ & Mass flow & $\mathrm{kg} / \mathrm{h}$ \\
\hline$M_{\mathrm{vP}} 1$ & Pressure before compression & $\mathrm{mbar}$ \\
\hline $\mathrm{M}_{\mathrm{vP}} 2$ & Pressure and temperature after comp. & $\mathrm{mbar}$ and ${ }^{\circ} \mathrm{C}$ \\
\hline $\mathrm{M}_{\mathrm{vP}} 3$ & Pressure after contraction & $\mathrm{mbar}$ \\
\hline $\mathrm{V}$ & Supercharger & - \\
\hline $\mathrm{M}$ & Electric Motor & - \\
\hline $\mathrm{HLM}$ & Hot Wire Air Flow Meter & - \\
\hline
\end{tabular}

Table 2. Description of the test bench measuring-points

The free programmable ECU is used to create for every crankshaft revolution one injection. It allows also creating special digital sensor curves, sensor maps and better engine control. Most of the sensor curves and sensor maps have to be evaluated by own testing. To explain exemplary how these maps are created, a closer look to the injector test equipment used for this project is given in Figure 5.

One injector is installed in a measurement unit, evaluating injection volume and rates, the other are actuated as dummies. A high-pressure fuel pump, driven by the bench motor, and the rail are assembled as well.

The injected volume is influenced by the injection pressure and the time while the injector valve is open. In the injector map, the opening time is written in $\mu$ s depending on pressure and volume. To create the map, a maximum volume is set in the ECU software by a constant fuel pressure set by the test bench software. The injection time is set manually in the injector map until the set volume matches with the tested volume. These procedure is done for every single point in the injector map.

\section{First test results}

To generally prove the expected advantage of the two-stroke engine initial tests on a vehicle dynamometer were performed, comparing a similar four-stroke version with the new concept engine. The test conditions are $50 \mathrm{~km} / \mathrm{h}$ at $5^{\text {th }}$ gear, corresponding to a city cruise with only approx. $3 \mathrm{~kW}$ power output. The first very promising test results are shown in Figure 6.

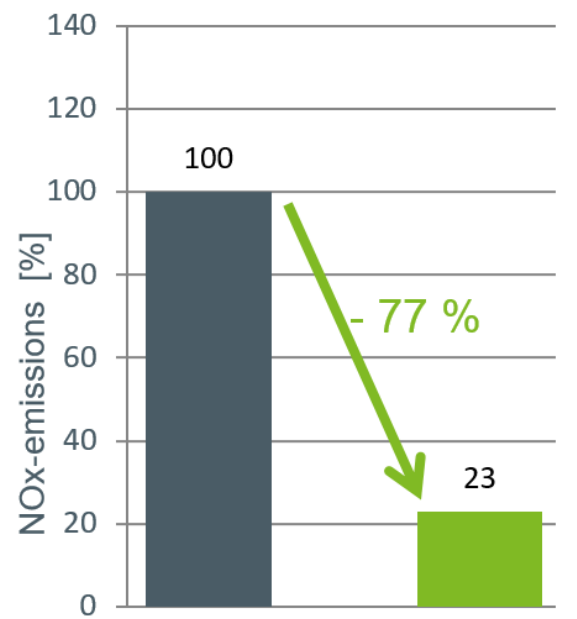

Four-stroke
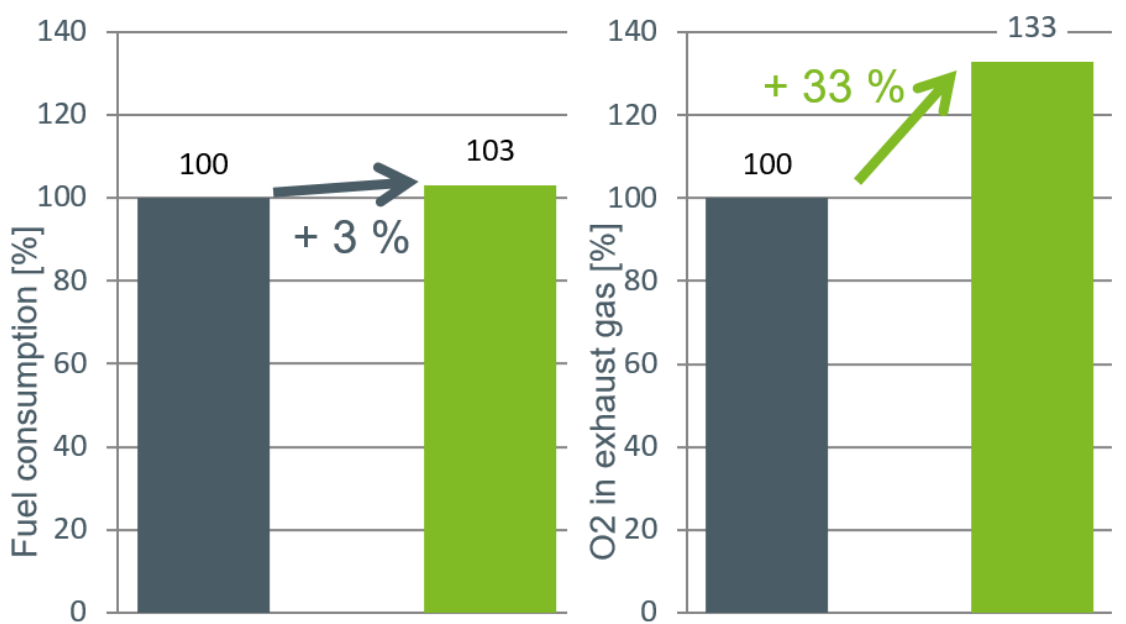

Two-stroke TSDI

Fig. 6. Comparison of test results (two-stroke vs. four-stroke)

It can be seen, that the two-stroke engine lowers $\mathrm{NO}_{\mathrm{x}}$-emission by $77 \%$. Just with initial ECU setting compared to the four-stroke engine the target, described in chapter 2, is already more than fulfilled. The reason for this tremendous $\mathrm{NO}_{\mathrm{x}}$ reduction is clearly visible in Figure 7, showing the comparison of the combustion pressure with both engines. Twostroke has double combustions process but a lower combustion pressure.

Simultaneously, fuel consumption has only increased by 3\%. Optimised ECU settings for an ideal two-stroke combustion will easily compensate this slight lack of efficiency ore will even increase the efficiency compared to serial production four-stroke engine. Hence, next step in this project will be to discover the full potential of the concept car by investigating the right ECU settings for each performance and engine load condition. 


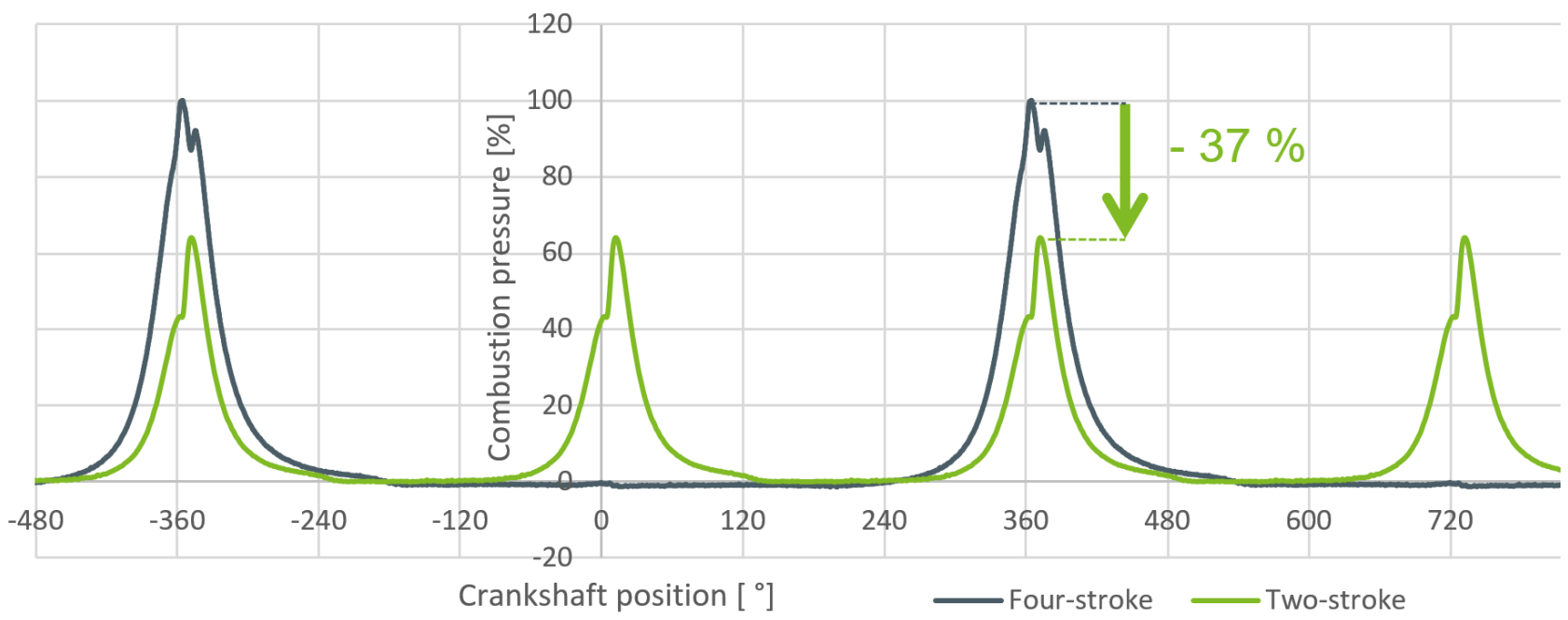

Fig. 7. Comparison of combustion pressure (two-stroke vs. four-stroke)

A further very promising result is shown in the right diagram of Figure 6, which illustrates the amount of $\mathrm{O}_{2}$ in the exhaust gas. This represents the potential for improvement for fresh air mass flow. The supercharger may produce, whilst being tested, too much scavenging air pressure. By reducing it, fuel consumption benefit and additional $\mathrm{NO}_{\mathrm{x}}$-emissions reduction can be expected. Summarized, initial tests without tuning or exact ECU settings confirm the expected benefits of a two-stroke direct injected diesel (TSDI) concept engine or even excel them, although further potential is clearly indicated. As further milestone for the next project phase, scientifically proven facts will substantiate the feeling of the authors, that engine noise and vibration is substantially improved by the two-stroke concept.

\section{Conclusion}

In the very early phase of the described project the prove of concept has already been given. A four-stroke engine out of serial production has been transformed successfully to a running demonstration car with a two-stroke diesel power train. Two-stroke diesel engines are a valid basis for an eco-friendly future vehicle. The cheaper price compared to a nowadays produced diesel cars makes the concept also affordable for a wide range of people in e.g. developing countries.

Initial tests showed that the theoretical basis is working excellent in a realistic engine concept. Future steps of the project will be to improve the initial test results concerning $\mathrm{NO}_{\mathrm{x}}$ and fuel consumption, but also to experimentally prove the additional potential regarding noise, vibration and hardness (NVH) and smoke level. ECU settings mast to be tune up, thus fuel consumption will be reduced by optimizing the injection settings. Because of the modified camshafts, a smaller open valve profile results in a lower fresh air supply into the cylinder. This limitation of gas flow leads to a loss in engine power output. To optimize the gas flow, another cam profile must be developed. Nevertheless, the successful build-up of the concept car with TSDI engine gives ideal conditions for all upcoming tests to prove the full potential of this new technology concept.

\section{References}

[1] Nationale Plattform Zukunft der Mobilität (2020). „Einsatzmoeglichkeiten unter realen Bedingungen“, Berlin

[2] M. Gloecke et al (2018) „Komponenten der Abgasnachbehandlung“, Handbuch Dieselmotoren, Springer, ISBN 978-3-658-07696-2, Wiesbaden

[3] welt, (2014). „Kuenftige Renault-Motoren“, Available from: https://www.welt.de/motor/news/article135288204/Kuenftige-Renault-Motoren.html , Accessed: 2020-09-01

[4] Theiss, S. (2020) „Inbetriebnahme und Abstimmung eines auf Zweitakt-Prinzip umgeruesteten ViertaktDieselmotors mit neu zu entwickelnder ECU“, Fiedberg

[5] Krüger, M.; Fischer, S. (2018) „Entstehung von Dieselschadstoffen und innermotorische Reduktionsmaßnahmen“, Handbuch Dieselmotoren, Springer, ISBN 978-3-658-07696-2, Wiesbaden

[6] A. Grabmeier, B. Las (2017) „Sensoren,“ Handbuch Verbrennungsmotor, Springer, ISBN 978-3-658-04677-4, Wiesbaden

[7] Iliev, S[imeon] \& Mitev, E[mil] (2019). "Modelling and Investigation of a Diesel Engine with Ethanol and Methanol Additives", Proceedings of the 30th DAAAM International Symposium, pp.0415-0423, B. Katalinic (Ed.), Published by DAAAM International, ISBN 978-3-902734-22-8, ISSN 1726-9679, Vienna, Austria

[8] Domenico De Serio et al (2017) "Effects of EGR rate on performance and emissions of a diesel power generator fueled by B7”, Journal of the Brazilian Society of Mechanical Sciences and Engineering volume 39 